\title{
Penerapan Corporate Social Responsibility (CSR) dan Manfaatnya Bagi Perusahaan
}

\author{
Ni Ketut Sri Ardani (1) \\ Luh Putu Mahyuni (2) \\ Toya Devasya ${ }^{(1)}$ \\ Universitas Pendidikan Nasional ${ }^{(2)}$ \\ sriardani21@gmail.com ${ }^{(1)}$ \\ ipmahyuni@gmail.com ${ }^{(2)}$
}

\begin{abstract}
This study aims to find out how the application of Corporate Social Responsibility and benefits to the company's in the Toya Devasya. This study used qualitative research methods. The data collection technique used is using the interview method and documentation. Data analysis used the Miles and Huberman Model data analysis techniques, which consisted of data reduction, data presentation and conclusion drawing. The results showed that the Toya Devasya implemented Corporate Social Responsibility based on Tri Hita Karana. Where Tri Hita Karana contains a meaning that is very complex because each element reflects the things that need to be implemented by each company. The company views that the implementation of Corporate Social Responsibility is important because it is a solution to the impact of business activities caused by the implementation of Corporate Social Responsibility carried out by the company that has been well received by the surrounding community. From the implementation of Corporate Social Responsibility it shows the existence of benefits that can be received by the company such as support from the community and comfort while working perceived by employees. The awareness that the company has to implement Corporate Social Responsibility will have a big impact on the company. The harmony created between the company, society and the environment is one of the impacts that will be felt by the company in carrying out its business activities. This harmony will have an effect on the company's image in the eyes of the community. The company will get support and be recognized in the environment around the company. Because of maintaining a good relationship with the surrounding environment, the community will voluntarily give their support to the Toya Devasya such as promoting the existence of the company to tourists so that there will be an increase in the number of visitors that will affect income.
\end{abstract}

Keywords : Corporate social repsonsibility; benefits to the company's 
Penelitian ini bertujuan untuk mengetahui bagaimana penerapan Corporate Social Responsibility dan manfaat bagi perusahaan pada Toya Devasya. Penelitian ini menggunakan metode penelitian kualitatif. Teknik pengumpulan data yang digunakan adalah dengan menggunakan metode wawancara dan dokumentasi. Analisis data menggunakan teknik analisis data Model Miles and Huberman, yang terdiri dari reduksi data, penyajian data dan penarikan kesimpulan. Hasil penelitian menunjukkan bahwa Toya Devasya menerapkan Corporate Social Responsibility berlandaskan Tri Hita Karana. Dimana Tri Hita Karana mengandung makna yang sudah sangat komplek karena setiap unsurnya mencerminkan hal yang perlu dilaksanakan oleh setiap perusahaan. Perusahaan memandang penerapan Corporate Social Responsibility penting dilakukan karena menjadi solusi dari dampak kegiatan bisnis yang ditimbulkan Pelaksanaan Corporate Social Responsibiliy yang dilakukan oleh perusahaan sudah dapat diterima dengan baik oleh masyarakat sekitar. Dari penerapan Corporate Social Responsibiliy ini menunjukan adanya manfaat yang dapat diterima oleh perusahaan seperti dukungan dari masyarakat dan kenyamanan saat bekerja yang dirasakan oleh karyawan. Kesadaran yang telah dimiliki perusahaan untuk menerapkan Corporate Social Responsibiliy akan memberikan dampak besar bagi perusahaan. Keharmonisan yang tercipta antara antara perusahaaan, masyarakat dan lingkungan merupakan salah satu dampak yang akan dirasakan perusahaan dalam menjalankan kegiatan bisnisnya. Keharmonisan inilah yang akan memberikan efek terhadap citra perusahaan dimata masyarakat. Perusahaan akan mendapatkan dukungan dan diakui keberadaannya di lingkungan sekitar perusahaan. Karena terjaganya hubungan yang baik dengan lingkungan sekitar, maka masyarakat pun akan dengan sukarela memberikan dukungannya terhadap Toya Devasya seperti mempromosikan keberadaan perusahaan kepada wisatawan sehingga terjadi peningkatan jumlah pengujung yang akan mempengaruhi pendapatan.

\section{Kata kunci : Corporate Social Responsibility; manfaat bagi perusahaan}




\section{PENDAHULUAN}

Corporate Social Responsibility atau tanggung jawab sosial perusahaan akhir-akhir ini semakin marak diperbincangkan di dunia baik media cetak, media elektronik maupun dalam seminar-seminar atau konferensi (Wahyuni dan Darma, 2019). Corporate Social Responsibility saat ini telah mengungkapkan bahwa perusahaan tidak lagi dihadapkan pada tanggung jawab yang berpijak pada single bottom line, yaitu nilai perusahaan (corporate value) yang direfleksikan dalam kondisi keuangannya (financial) saja (Darma, 2019). Tanggung jawab perusahaan juga harus berpijak pada triple bottom lines, yang terdiri dari financial, sosial dan lingkungan (Darma, 2018). Hal ini harus diperhatikan karena kondisi keuangan saja tidak cukup menjamin nilai perusahaan tumbuh secara berkelanjutan atau sustainable (Dewi dan Darma, 2019) . Munculnya kesadaran bahwa kegiatan produksi suatu perusahaan secara tidak langsung memberikan dampak negatif bagi lingkungan sosial maupun lingkungan fisik di sekitar tempat kegiatan produksi, membuat perusahaan merasa penting untuk melakukan kegiatan yang bersifat sosial (Manika Sari, 2017; Budiasni dan Darma, 2016). Corporate Social Responsibility diatur dalam Undang-Undang Republik Indonesia Nomor 40 Tahun 2007 Tentang Perseroan Terbatas Pasal 74 Tanggungjawab Sosial dan Lingkungan. Sehingga mewajibkan perusahaan untuk melakukan aktivitas tanggungjawab sosial. Sejak ditetapkannya perundang-undangan yang mengatur Corporate Social Responsibility, semakin banyak perusahaan yang melakukan program Corporate Social Responsibilityuntuk menjaga reputasi dan keberlangsungan usahanya( Rilla Gantino, 2016; Wahyuni dan Darma, 2019).

Dalam penelitian tentang standarisasi praktik Corporate Social Responsibility mengungkapkan bahwa pelaksanaan Corporate Social Responsibility di Indonesia sangat tergantung pada pimpinan puncak korporasi (Bali dan Darma, 2019). Artinya, kebijakan Corporate Social Responsibility tidak selalu dijamin selaras dengan visi dan misi korporasi. Jika pimpinan perusahaan memiliki kesadaran moral yang tinggi, besar kemungkinan korporasi tersebut menerapkan kebijakan Corporate Social Responsibility yang benar. Sebaliknya, jika orientasi pimpinannya hanya berkiblat pada kepentingan kepuasan pemegang saham (produktivitas tinggi, profit besar, nilai saham tinggi) serta pencapaian prestasi pribadi, boleh jadi kebijakan Corporate Social Responsibility hanya sekadar "kosmetik".

Dikarenakan masih adanya kontroversi yang timbul mengenai praktik Corporate Social Responsibility, maka penelitian dengan topik Penerapan Corporate Social Responsibility Dan Manfaatnya Bagi Perusahaan Studi Kasus Pada Toya Devasya penting dilakukan. Toya Devasya merupakan salah satu perusahaan yang bergerak dibidang hospitality didirikan sejak tahun 2002 yang berada dipinggiran Danau Batur, di desa Toya Bungkah, Kintamani, Bangli. 
Toya Devasya memulai usahanya sebagai profit-sharing cooperation, melibatkan \& memberdayakan orang Bali khususnya masyarakat Toya Bungkah dan Songan dalam menjalankan dan mengembangkan bisnisnya. Tujuan dari penelitian ini adalah untuk mengetahui bagaimana penerapan Corporate Social Responsibility pada Toya Devasya dan Untuk mengetahui manfaat penerapan Corporate Social Responsibility bagi perusahaan pada Toya Devasya.

\section{Teori Stakeholder}

Stakeholder pada dasarnya dapat mengendalikan atau memiliki kemampuan untuk mempengaruhi pemakaian sumber-sumber ekonomi yang digunakan perusahaan (Ghozali dan Chariri: 2007; Wiandari dan Darma, 2017). Power stakeholder dapat berupa kemampuan untuk membatasi pemakaian sumber ekonomi yang terbatas (modal dan tenaga kerja), akses terhadap media yang berpengaruh, kemampuan untuk mengatur perusahaan, atau kemampuan untuk mempengaruhi konsumsi atas barang dan jasa yang dihasilkan perusahaan (Brown dan Deegan:1998; Juzer dan Darma, 2019). Jadi kemudian muncullah statement bahwa ketika stakeholder mengendalikan sumber ekonomi yang penting bagi perusahaan, maka perusahaan akan bereaksi dengan cara-cara yang memuaskan keinginan stakeholder (Ullman: 1982 dalam Putri, 2017; Dewi dan Darma, 2018).

Teori stakeholder menyatakan bahwa stakeholder berpengaruh secara komplek dan dinamis terhadap pandangan tentang suatu organisasi dan lingkungannya, saling mempengaruhi sifat aslinya antara keduanya secara kompleks dan dinamis. Hal ini berlaku untuk kedua unsur teori stakeholder, unsur pertama berhubungan langsung dengan model akuntabilitas. Stakeholder dan organisasi saling mempengaruhi, hal ini dapat dilihat dari hubungan sosial keduanya yang berbentuk responsibilitas dan akuntabilitas. Oleh karena itu organisasi memiliki akuntabilitas terhadap stakeholdernya.

Hubungan antara stakeholder dan organisasi ditentukan dari sifat akuntabilitas. Unsur dari kedua teori stakeholder berhubungan dengan pandangan Trekers (1983) dalam Achmad (2007) mengenai emprical accountability. Robert(1992) menyatakan bahwa pengungkapan sosial perusahaan merupakan sarana yang sukses bagi perusahaan untuk menegosiasikan hubungan dengan stakeholdernya.

\section{Tanggungjawab Sosial Perusahaan (Corporate Social Responsibility)}

Tanggung Jawab Sosial Perusahaan adalah suatu komitmen keberlanjutan untuk memberi dampak positif terhadap lingkungan dan masyarakat dimana perusahaan tersebut 
disamping berada di kegiatan bisnisnya, guna menyeimbangkan tanggung jawab perusahaan dalam menghasilkan laba tetapi juga bermanfaat bagi masyarakat dan lingkungan (Hamdani, 2013; Budiasni dan Darma, 2016).

Sedangkan menurut penelitian yang dilakukan Post et al, yang dialih bahasakan oleh Ismail Solihin (2015) Pengertian Corporate Social Responsibility adalah tanggung jawab perusahaan terhadap berbagai tindakan yang mempengaruhi manusia, komunitas, maupun lingkungan secara umum. Dari beberapa definisi tersebut dapat disimpulkan bahwa pengertian Corporate Social Responsibility merupakan sebuah bentuk pertanggungjawaban sosial perusahaan yang berpijak pada konsep triple bottom line yaitu profit (keuntungan), people (masyarakat), planet (lingkungan). Perusahaan menyadari bahwa fokus utama bukan hanya profit atau keuntungan melainkan perusahaan harus lebih memperhatikan dimensi sosial dan lingkungan yang secara tidak langsung berdampak pada keberlanjutan usaha.

\section{Manfaat Corporate Social Responsibility Bagi Perusahaan}

Dalam buku, "Membedah Konsep dan Aplikasi CSR", Yusuf Wibisono (2007:99) menjelaskan manfaat atau keuntungan yang didapatkan oleh perusahaan ketika menerapkan program Corporate Social Responsibility (CSR) yang dilihat dari aspek stakeholder dari CSR itu sendiri, yang pertama bagi perusahaan yaitu dapat tumbuh dan berkembang serta memiliki citra yang baik dimata masyarakat sehingga mengalami keberlanjutan usaha, mempermudah akses perusahaan dalam menmperoleh modal (capital), Perusahaan mampu menciptakan dan dapat mempertahankan sumber daya manusia (human resources) yang berkualitas, Perusahaan dapat meningkatkan pengambilan sebuah keputusan bila terjadi hal-hal yang kritis (critical decision making) dan mengelola dengan baik manajemen risiko atau risk management (Dewi dan Darma, 2019)

Kedua bagi masyarakat yaitu penerapan CSR dengan cara menyerap SDM lokal akan memberikan nilai-tambah terhadap keberadaan perusahaan disuatu daerah sehingga meningkatkan kualitas sosial didaerah tersebut. Pekerja lokal yang diserap akan mendapatkan perlindungan akan hak-haknya sebagai pekerja. Praktik CSR akan menghormati tradisi dan kebudayaan masyarakat lokal.

Ketiga bagi Lingkungan yaitu praktik CSR akan mengurangi penggunaan sumber daya alam secara berlebihan, menjaga kualitas lingkungan dengan menekan tingkat polusi dan perusahaan ikut terlibat memperbaiki dan menjaga lingkungannnya. Hal ini pastinya untuk tetap mempertahankan keberlangsungan lingkungan itu sendiri. 
Keempat bagi Negara yaitu praktik CSR yang baik akan mencegah malpraktik bisnis seperti penyuapan pada aparat negara atau aparat hukum yang memicu tingginya korupsi. Selain itu, negara akan menikmati pendapatan dari pajak yang wajar (yang tidak digelapkan) oleh perusahaan. Karena instrumen ini merupakan salah satu pendapatan paling besar dalam pendapatan per kapita Negara.

\section{METODE PENELITIAN}

Toya Devasya yang beralamat di jalan Toya Bungkah Kintamani, Bangli, Bali. Adapun alasan memilih lokasi penelitian ini dikarenakan Toya Devasya merupakan salah satu perusahaan hospitality yang mengembangkan bisnisnya dengan berlandaskan Tri Hita Karana. Toya Devasya menjalankan bisnis sebagai Profit-Sharing coorporate.

Jenis data yang digunakan dalam penelitian ini adalah data kualitatif dan kuantitatif. Data kualitatif dianalisis dengan cara menganalisis hasil wawancara mendalam dan hasil dokumentasi di lapangan. Sedangkan data kuantitatif dianalisis dengan cara melihat laporan keuangan perusahaan berupa biaya dan pendapatannya. Penelitian ini menggunakan dua data yaitu data primer dan data sekunder. Data primer dalam penelitian ini adalah hasil wawancara serta hasil dokumentasi yang dilakukan oleh peneliti. Data sekunder adalah data yang diperoleh secara tidak langsung melalui media perantara, seperti orang lain atau dokumen.

Teknik pengumpulan data dalam penelitian ini berupa wawancara dan dokumentasi. Wawancara melakukan tanya jawab secara langsung dengan pihak perusahaan bagian yang menaungi program Corporate Social Responsibility untuk mengetahui lebih jelas mengenai implementasi yang berkaitan dengan Corporate Social Responsibility serta informasi yang berkaitan dengan perusahaan. Dokumentasi dilakukan dengan melihat dan menganalisi data yang telah ada di perusahaan, seperti sejarah perusahaan, struktur organisasi, Laporan Pertanggungjawaban sosial perusahaan, dan laporan keuangan perusahaan

Informan yang menjadi sumber untuk memperoleh data pada penelitian ini adalah CEO (Chief Executive Officer), karyawan Toya Devasya dan masyarakat yang menerima program Corporate Social Responsibility. Karyawan tersebut merupakan karyawan di Divisi Public Relation atau yang menangani langsung program Corporate Social Responsibility.

Teknik analisis data yang digunakan dalam penelitian ini adalah teknik analisis data Model Miles and Huberman. Yaitu Mereduksi data berarti merangkum, memilih hal-hal pokok, memfokuskan pada hal-hal penting, dicari tema dan polanya. Kedua Penyajian data, semua data yang telah direduksi akan disajikan dalam bentuk tabel, grafik maupun narasi. Melalui penyajian data tersebut, maka data terorganisasikan, tersusun dalam pola hubungan, sehingga 
mudah dipahami. Ketiga penarikan kesimpulan, jika kesimpulan yang diperoleh pada tahap awal didukung oleh bukti-bukti yang valid dan konsisten saat penulis kembali ke lapangan mengumpulkan data, maka kesimpulan yang diperoleh merupakan kesimpulan yang kredibel.

Pada penelitian ini, peneliti menggunakan triangulasi sumber dan triangulasi teknik. Triangulasi sumber dilakukan dengan membandingkan hasil wawancara dari sumber internal dengan sumber eksternal, misalnya dari pihak karyawan dengan masyarakat sekitar perusahaan. Triangulasi teknik dilakukan dengan membandingkan hasil wawancara dengan dokumentasi.

\section{PEMBAHASAN}

Dari penelitian ini menemukan bahwa penerapan Corporate Social Responsibility (CSR) berawal dari kesadaran perusahaan untuk lebih memperhatikan lingkungan sekitarnya yang dilaksanakan secara terintegrasi dan berkelanjutan, baik untuk sumber daya manusianya ataupun terkait dengan alam dan budaya sekitar. Toya Devasya menerapkan praktik CSR berlandaskan pada konsep Tri Hita Karana dikarenakan konsep ini memiliki tiga hal penting untuk menjaga kondisi perusahaan tetap baik. Tiga hal tersebut yaitu Parahyangan yang artinya menjaga hubungan baik manusia dengan Tuhan, Pawongan yaitu menjaga hubungan baik manusia dengan manusia dan Palemahan yaitu menjaga hubungan baik manusia dengan lingkungan alam.

Penerapan Corporate Social Responsibility yang dilakukan oleh Toya Devasya yaitu berupa mempekerjakan orang lokal untuk bekerja disana dan memberikan pelatihan dibidangnya masing-masing hal ini dimaksudkan untuk dapat menghasilkan SDM yang lebih berkualitas agar mampu memberikan pelayanan yang baik dan karyawan memiliki kemampuan untuk bersaing didunia hospitality. Selain itu perusahaan memberikan pengobatan gratis serta pembagian sembako untuk warga di wilayah Kintamani. Perusahaan juga memberikan bantuan ke Pura yang berada di daerah Kintamani saat upacara agama berlangsung baik berupa perlengkapan upacara maupun bantuan dalam pembersihan Pura. Upacara pekelem yang dilakukan pihak perusahaan di Danau Batur juga merupakan praktik CSR yang dilakukan perusahaan, hal ini bertujuan untuk menjaga keharmonisan alam semesta. Pembangunan tempat ibadah juga merupakan praktik CSR Toya Devasya dengan tujuan membebaskan karyawan dalam melakukan ibadahnya dan tetap menjaga hubungn baik kepada Tuhan Yang Maha Esa. Praktik CSR lainnya yang dilakukan perusahaan adalah melakukan pembersihan area Danau Batur dan menanam pohon kopi. 
Dari praktik-praktik CSR tersebut membuktikan bahwa perusahaan telah melakukan praktik CSR dengan baik dan tidak hanya mementingkan kepentingan perusahaan semata. Perusahaan juga memikirkan bagaimana membuat keberadaan Toya Devasya bisa bermanfaat untuk masyarakat sehingga dapat terjalin hubungan kemitraan baik antara perusahaan dengan lingkungan sekitar.

Hal ini sesuai dengan penelitian yang dilakukan Merin Noviana (2016) dan Wiadnyani Putri (2017) yang menyatakan dari perspektif karyawan dan manajemen menunjukan bahwa tujuan dan maksud dari implementasi program CSR dapat diterima dengan baik oleh masyarakat sekitar dan dianggap penting untuk menjalin hubungan yang baik dengan masyarakat. Penelitian sejenis juga menyebutkan bahwa pertanggungjawaban sosial memiliki pengaruh terhadap nilai perusahaan karena program CSR secara tidak langsung memberikan keuntungan untuk perusahaan. Hal tersebut dapat meningkatkan nilai perusahaan dimata masyarakat maupun stakeholder lainnya.

Penelitian ini menemukan bahwa penerapan Corporate Social Responsibility memberikan manfaat yang besar untuk perusahaan. Dengan mempekerjakan masyarakat lokal dan membantu masyarakat sekitar ternyata perusahaan merasakan dukungan yang diberikan masyarakat sekitar. Dukungan tersebut berupa bantuan untuk mempromosikan atau menawarkan wisatawan yang berada di wilayah Kintamani khususnya untuk berkunjung ke Toya Devasya. Perusahaan merasakan bahwa kebanyakan tamu asing yang berkunjung diantarkan langsung oleh masyarakat sekitar. Dalam praktik CSR yang lain seperti pelatihan untuk karyawan ternyata memberikan manfaat yang besar juga untuk perusahaan seperti kepuasan tamu yang berkunjung ke Toya Devasya. Pelatihan tersebut bertujuan untuk meningkatkan kualitas SDM dan berdampak besar untuk pelayanan yang diberikan. Hal ini sesuai dengan penelitian Ngurah Krisna Pernama (2017) yang menjelaskan bahwa image, citra perusahaan dan pandangan masyarakat terhadap perusahaan semakin berubah kearah yang positif, karena keberpihakan perusahaan terhadap stakeholder dalam hal baik produk, lingkungan masyarakat dan transparan terhadap informasi-informasi yang dibutuhkan stakeholder. Hal yang sama juga diungkapkan oleh Desy Aprianthiny (2015) yang melakukan penelitian dengan topik yang sama tetapi menjadikan Corporate Social Responsibility sebagai modal sosial perusahaan tersebut. Hasil penelitian ini menunjukan program yang dilakukan mendapat dukungan penuh dari masyarakat karena memiliki banyak manfaat bagi masyarakat. Tidak hanya bermanfaat bagi masyarakat tetapi juga bermanfaat untuk perusahaan itu sendiri karena mampu membangun kepercayaan dari para stakeholder. 


\section{PENUTUP}

Berdasarkan dari hasil penelitian yang dilakukan di Toya Devasya dan hasil pembahasan diatas, dapat disimpulkan bahwa penerapan Corporate Social Responsibiliy di Toya Devasya menggunakan konsep Tri Hita Karana. Dimana Tri Hita Karana mengandung makna yang sudah sangat komplek karena setiap unsurnya mencerminkan hal yang perlu dilaksanakan oleh setiap perusahaan. Perusahaan memandang penerapan Corporate Social Responsibility penting dilakukan karena menjadi solusi dari dampak kegiatan bisnis yang ditimbulkan. Pelaksanaan Corporate Social Responsibiliy yang dilakukan oleh perusahaan sudah dapat diterima dengan baik oleh masyarakat sekitar. Dari penerapan Corporate Social Responsibiliy ini menunjukan adanya manfaat yang dapat diterima oleh perusahaan seperti dukungan dari masyarakat dan kenyamanan saat bekerja yang dirasakan oleh karyawan. Kesadaran yang telah dimiliki perusahaan untuk menerapkan Corporate Social Responsibiliy akan memberikan dampak besar bagi perusahaan. Keharmonisan yang tercipta antara antara perusahaaan, masyarakat dan lingkungan merupakan salah satu dampak yang akan dirasakan perusahaan dalam menjalankan kegiatan bisnisnya. Keharmonisan inilah yang akan memberikan efek terhadap citra perusahaan dimata masyarakat. Perusahaan akan mendapatkan dukungan dan diakui keberadaannya di lingkungan sekitar perusahaan. Karena terjaganya hubungan yang baik dengan lingkungan sekitar, maka masyarakat pun akan dengan sukarela memberikan dukungannya terhadap Toya Devasya seperti mempromosikan keberadaan perusahaan kepada wisatawan sehingga terjadi peningkatan jumlah pengujung yang akan mempengaruhi pendapatan. Penerapan Corporate Social Responsibility sangat memberikan dampak yang positif terhadap perusahaan baik jangka pendek maupun jangka panjang karena dukungan dari masyarakat dan kenyamanan dalam bekerja adalah suatu modal untuk dapat memuaskan tamu yang berkunjung. 


\section{DAFTAR PUSTAKA}

Ambadar, J. (2008). Corporate Social Responsibility dalam Praktik di Indonesia. PT Elex Media Komputindo.

Asongu, J.J. (2007). The Legitimacy of Strategic Corporate Social Responsibility as a marketing Tool, Journal of Business and Public Policy, 1 (1).

Apriantini, K.D. (2015). Implementasi Corporate Social Responsibility (CSR) Sebagai Modal Sosial Pada PT. Tirta Mumbul Jaya Abadi, Singaraja Bali. Universitas Pendidikan Ganesha. Singaraja-Bali.

Bali, I.N.A.P., and Darma, G.S. (2019). Menguji Kesiapan Pengelolaan Desa Berbasis Manajemen Modern Guna Menghadapi Era Revolusi Industri 4.0, Jurnal Manajemen \& Bisnis, 16 (2): 1-13.

Branco, M.C., dan Rodriguez, L.L. (2007). Positioning Stakeholder Theory within the Debate on Corporate Social Responsibility, EJBO (Electronic Journal of Business Ethics and Organization Studies, 12 (1).

Budiasni, N.W.N., and Darma, G.S. (2016). Penerapan Corporate Social Responsibility pada Lembaga Keuangan Berbasis Kearifan Lokal, Jurnal Manajemen \& Bisnis, 13 (2): 119.

Chariri, A. (2008). Kritik Sosial atas Pemakaian Teori dalam Penelitian Pengungkapan Sosial dan Lingkungan, Jurnal Maksi, 8 (2): 151-169.

Darma, G.S. (2019). Kacamata Media, Kesuksesan Bersyarat. Indonesia: Pustaka Larasan Press.

Darma, G.S. (2018). Seuntai Pesan, Menjawab Zaman. Indonesia: Pustaka Larasan Press.

Darma, G.S. (1999). Information Technology and Organisational Performance: A Study of the Hospitality Industry, Southern Cross University, Lismore New South Wales Australia.

Darma, G.S. (2006). The Impact of Information Technology Investment on the Hospitality Industry, Jurnal MAKSI, 6 (1): 1-22.

Daud, R.M., dan Amri, A. (2008). Pengaruh Intellectual Capital dan Corporate Social Responsibility terhadap Kinerja Perusahaan (Studi Empiris pada Perusahaan Manufaktur di BEI), Jurnal Telaah \& Riset Akuntansi, 1 (2): 213-231.

Dewi, N.K.Y.W., and Darma, G.S. (2019). Strategi Investasi \& Manajemen Resiko Rumah Sakit Swasta di Bali, Jurnal Manajemen \& Bisnis, 16 (2): 110-127.

Dewi, N.M.A.T., and Darma, G.S. (2016). Efektivitas Leadership, Growth Performance dan Regulasi Otoritas Jasa Keuangan, Jurnal Manajemen \& Bisnis, 13 (1): 1-13.

Freeman, R.E. (1984). Strategic Management: A Stakeholder Approach. Pitman, Boston. 
Gantino, R. (2016). Pengaruh Corporate Sosial Responsibility Terhadap Kinerja Keuangan Perusahaan manufaktur Yang Terdaftar di Bursa Efek Indonesia Periode 2008-2014, Jurnal Dinamika Akuntansi Dan Bisnis, 3 (2): 19-32.

Ghoul, S.E., Omrane, G., Chuck, C.Y.K., and Mishra, D.R.. (2011). Does Corporate Social Responsibility affect the cost of capital, Journal of Banking \& Finance, 35 (9) : 23882406.

Gossling, T., dan Vocht, C. (2007). Social Role Conceptions and Corporate Social Responsibility Policy Success, Journal of Business Ethics, 74: 363-372.

Jensen, M.C. (2001). Value Maximisation, Stakeholder Theory, and the Corporate Objective Function, European Financial Management, 7 (3): 297-317.

Juzer, J., and Darma, G.S. (2019). Strategic Supply Chain Management in the Era of Industry Revolution 4.0 : A Study of Textile Industry in Bali, Jurnal Manajemen Bisnis, 16 (3): $1-16$.

Kamil, A., dan Herusetya, A. (2012). Pengaruh Karakteristik Perusahaan Terhadap Luas Pengungkapan Kegiatan Corporate Social Responsibility, Media Riset Akuntansi, 2 (1): $1-17$.

Kamantra, N., dan Dyah, E.K. (2015). Effect Corporate Social Responsibility on Financial Performance. Universiti Teknologi Malaysia, Kuala Lumpur, malaysia, International Journal of Economics and Financial issues: 157-164.

Lako, A. (2011). Dekonstruksi CSR dan Reformasi Paradigma Bisnis dan Akuntansi. Jakarta: Erlangga.

Noviana, M. (2016). Analisis Perspektif Stakeholder Terhadap Implementasi Corporate Social Responsibility pada Padma Resort Legian. Universitas Pendidikan Nasional. Denpasar. Sari, D.A.M., Sinarwati, N.K., dan Wahyuni, M.A. (2017). Implementasi Corporate Social Responsibility (CSR) Dan Dampaknya Terhadap Kinerja Keuangan Pada Industri Perhotelan (Studi Kasus Pada Melia Bali Hotel). Universitas Pendidikan Ganesha. Singaraja.

Sindhudiptha, I.N.S.Y. (2013). Pengaruh Corporate Social Responsibility Pada Kinerja Keuangan Perusahaan dan Implikasinya Terhadap Nilai Perusahaan. Universitas Udayana. Denpasar-Bali.

Sugiyono. (2016). Metode Penelitian Kuantitatif, Kualitatif, dan R\&D. Bandung: Alfabeta. Susanto, A.B. (2007). Corporate Social Responsibility. Jakarta: The Jakarta Consulting Group. 
Swari, D.A.K.B.A., and Darma, G.S. (2019). Kepercayaan Lintas Generasi Dalam Penggunaan Social Media dan Electronic Word of Mouth, Jurnal Manajemen Bisnis, 16 (4): 145161.

Umawan, A.A.N.K.P. (2017). Analisis Penerapan Dan Dampak Pengungkapan Corporate Social Responsibility Di Hotel The Westin Resort Nusa Dua. Universitas Udayana. Bali.

Wahyuni, N.W.S., and Darma, G.S. (2019). Mobile Advertising, Product Social Value dan Purchase Intention pada Instagram, Jurnal Manajemen Bisnis, 16 (4): 87-101.

Wiandari, I.A.A., and Darma, G.S. (2017). Kepemimpinan, Total Quality Management, Perilaku Produktif Karyawan, Kinerja Karyawan dan Kinerja Perusahaan, Jurnal Manajemen \& Bisnis, 14 (2): 61-78

Wiadnyani, P. (2017). Analisis Perspektif Stakeholder Terhadap Implementasi Corporate Social Responsibility (CSR) Berlandaskan Nilai Budaya Tri Hita Karana dan Perlakuan Akuntansinya Pada Discovery Kartika Plaza Hotel. Universitas Pendidikan Nasional. Denpasar.

Yusdantara, I.K. (2015). Pengaruh Corporate Social Responsibility Terhadap Reputasi Perusahaan Yang Dimediasi Oleh Kepuasan Pelanggan (Studi Pada PT. Coca Cola Amatil Denpasar). Universitas Udayana. Denpasar-Bali, 4 (4): 813-831. 